\title{
Article \\ Influence of Depression and Anxiety on Hemodialysis Patients: The Value of Multidisciplinary Care
}

\author{
Carlos J. Delgado-Domínguez ${ }^{1, * \mathbb{D}}$, Sergio Sanz-Gómez ${ }^{2} \mathbb{D}$, Ana López-Herradón ${ }^{3}$, Beatriz Díaz Espejo ${ }^{1}$, \\ Olaya Lamas González ${ }^{3}$, Macarena de los Santos Roig ${ }^{4}$ (D) Isabel Berdud Godoy ${ }^{1}$ (D) Abraham Rincón Bello ${ }^{3} \mathbb{D}$ \\ and Rosa Ramos Sánchez ${ }^{3}$
}

check for updates

Citation: Delgado-Domínguez, C.J.; Sanz-Gómez, S.; López-Herradón, A.; Díaz Espejo, B.; Lamas González, O.; de los Santos Roig, M.; Berdud Godoy, I.; Rincón Bello, A.; Ramos Sánchez, R. Influence of Depression and Anxiety on Hemodialysis Patients: The Value of Multidisciplinary Care. Int. J. Environ. Res. Public Health 2021, 18, 3544. https://doi.org/10.3390/ ijerph18073544

Academic Editors: Tomasz Porażko, Tomasz Gołębiowski,

Andrzej Konieczny,

Hanna Augustyniak-Bartosik and Magdalena Kuriata-Kordek

Received: 26 February 2021

Accepted: 24 March 2021

Published: 29 March 2021

Publisher's Note: MDPI stays neutral with regard to jurisdictional claims in published maps and institutional affiliations.

Copyright: (c) 2021 by the authors. Licensee MDPI, Basel, Switzerland. This article is an open access article distributed under the terms and conditions of the Creative Commons Attribution (CC BY) license (https:/ / creativecommons.org/licenses/by/ $4.0 /)$.
1 Centro de Hemodiálisis San Rafael, Fresenius Medical Care Services Andalucía (FMCSA), Calle Julio Arteche, 1, 14005 Córdoba, Spain; beatriz.diaz@fmc-ag.com (B.D.E.); isabel.berdud@fmc-ag.com (I.B.G.)

2 Departamento de Psiquiatría, Facultad de Medicina, Universidad de Sevilla, Avenida Sánchez Pizjuán, s/n, 41009 Sevilla, Spain; ssanz1@us.es

3 Departamento Médico, Fresenius Medical Care España, Ronda de Poniente, 8, 28760 Madrid, Spain; ana.lopez@fmc-ag.com (A.L.-H.); olaya.lamas@gmail.com (O.L.G.); abraham.rincon@fmc-ag.com (A.R.B.); 30965rrs@gmail.com (R.R.S.)

4 Departamento de Metodología de las Ciencias del Comportamiento, Facultad de Psicología, Campus de Cartuja, s/n, Universidad de Granada, 18011 Granada, Spain; dlsantos@ugr.es

* Correspondence: carlosdelgadoxp@gmail.com

Abstract: Affective disorders promote poorer outcomes in hemodialysis patients. According to the presence or not of depression/anxiety in these patients, aims were to analyze differences in sociodemographic, clinical and/or psychological factors and to identify predictors. One hundred eighty-six hemodialysis patients were classified based on their depression/anxiety status. Basal characteristics showed differences between groups where mainly male sex (Depression: OR 0.2; Anxiety: OR 0.3) albumin (Depression: OR 0.1; Anxiety: OR 0.2) and calcium levels (Depression: OR 0.5; Anxiety: OR 0.4), impaired quality of life (Depression: OR 1.4; Anxiety: OR 1.2) and psychological inflexibility (Depression: OR 1.3; Anxiety: OR 1.2) were associated (all $p<0.01$ ) to these mental conditions. Multivariate models showed that worse quality of life (OR 1.3; $p<0.001$ ) predicted depression while marital status (with a partner; OR $0.3 ; p=0.025$ ) and albumin levels (OR 0.1; $p=0.027$ ) were protective factors. Depression represented a risk factor for anxiety (OR 1.2; $p=0.001$ ), although calcium levels (OR $0.5 ; p=0.039$ ) would protect this state. Interestingly, psychological inflexibility predicted both disorders (Depression: OR 1.2, $p<0.001$ and Anxiety: OR $1.1 ; p=0.002$ ). Results highlight the relevance of well-trained multidisciplinary hemodialysis units to control the influence of these factors on the presence of depression/anxiety, and thus, their impact on the patients' outcomes.

Keywords: anxiety; depression; psychological inflexibility; hemodialysis; quality of life

\section{Introduction}

Affective disorders are well-known risk factors for health and quality of life of patients on hemodialysis (HD) treatment [1]. In the last 20 years, great efforts have been made in the field of nephrology and health psychology to detect and account for the high prevalence of affective disorders in patients with chronic kidney disease (CKD) who should be cared for in HD units. Some works published in the 2000s have already highlighted that depressive patients undergoing HD had a higher mortality rate than those who do not [2,3]. More recently, depressed mood has also been associated with up to four times more of withdrawal from HD treatment and an increased risk of hospitalizations [3-5]. Alcohol dependence, abuse of other addictive substances or other mental health problems with the subsequent increased risk of death by suicide are other relevant study variables to be considered in these particular patients [6]. 
Anxiety, although less studied than depression in the context of CKD, is a psychological disorder that strongly impacts the health state and quality of life of patients on HD treatment $[1,4,7]$. Therefore, it is considered that this condition is directly related to poorer clinical outcomes derived from HD, promoting less patients' adherence to their treatment and impairing also the nutritional habits which increases mortality rates [7]. Despite all the evidence highlighting the impact of depression and anxiety in CKD patients, the introduction of health psychologists in HD units staffing is still limited as well as the therapeutic tools to work with these particular patients. This impact needs to be seriously supervised in HD units and even more when it is well documented that many patients, despite years of HD therapy, often continue experiencing anxiety during the weekly sessions they receive [4].

Psychological inflexibility (PI) has been proposed as a process that underlies both disorders and facilitates their emergence and course [8]. This construct is defined as " $a$ rigid pattern of behavior in which a person directs their actions on the basis of momentary private experiences rather than freely chosen values" [9]. PI and experiential avoidance are theorized to contribute to the development, maintenance and exacerbation of a wide range of psychological problems. Although the form of problem behaviors differs between disorders, many of them can be conceptualized as sharing common psychological functions [10]. However, in the field of HD, there is no research addressing this key concept in clinical psychology.

Patients with CKD and particularly those undergoing HD, often require mental health support due to anxious-depressive conditions. However, it is uncommon that the presence of multidisciplinary teams in HD units are able to analyze and follow-up on parameters involved in mental health and the quality of life of the patients. Therefore, based on the presence or not of depression or anxiety in our patients, the aims of this study were to compare different sociodemographic, psychological, clinical and HD-related parameters between groups and also to identify predictors for these conditions.

\section{Materials and Methods}

\subsection{Participants}

A multi-centre prospective cross-sectional study was carried out in outpatients in the HD programme at Fresenius Medical Care clinics in the province of Córdoba (Spain). The inclusion criteria were: (1) Ability to understand and speak the Spanish language; (2) Age between 18 and 90 years old; (3) Signed informed consent for the study; (4) HD vintage of at least six months; and (5) Absence of cognitive impairment or severe mental disorder. A total of 130 patients were excluded from the potential sample of the four clinics $(\mathrm{N}=316)$, which resulted in a total sample of 186 subjects ( $58 \%$ of participation rate). All patients had previously been informed about data privacy and had provided written informed consent for the use of their data to conduct scientific research. The Research Ethics Committee from Hospital Universitario Reina Sofía (Córdoba, Spain) authorized this study in June 2017.

\subsection{Sociodemographic and Clinical Variables}

Data on sociodemographic characteristics, Charlson Comorbidity Index (CCI), dialysis modality and quality parameters, concomitant medication and laboratory results were collected from the EuCliD database, belonging to Fresenius Medical Care [11]. All blood samples were drawn pre-dialysis. Kt/V was used as indicator of dialysis quality and monitored in every dialysis treatment using the $\mathrm{OCM}^{\circledR}($ On-line Clearance Monitor; Fresenius Medical Care, Bad Homburg, Germany). The mean of all Kt/V values during the month was obtained. The Body Composition Monitor $\left(\mathrm{BCM}^{\circledR}\right.$; Fresenius Medical Care, Bad Homburg, Germany) estimated body composition parameters, including lean and fat tissue indexes (LTI and FTI) and overhydration, calculated as predialysis weight minus normohydrated weight and adjusted per extracellular water. All $\mathrm{BCM}^{\circledR}$ measurements were performed before the dialysis session and after $10 \mathrm{~min}$ in decubitus. 


\subsection{Psychological and Quality of Life Variables}

Different questionnaires for the assessment of patients' quality of life and mental state were completed during the months of June and July 2017. During the HD sessions, all these questionnaires were provided and explained to the patients by three staff members previously trained, with a completion time of 20-30 min.

The following instruments were administered:

Coop-Wonca Quality of Life Charts [12]. It is a general questionnaire for the evaluation of health-related quality of life (HRQoL) in 9 dimensions: 1. Physical fitness, 2. Feelings, 3. Daily life activities, 4 . Social activities, 5 . Changes in health status, 6 . Health status, 7. Pain, 8. Social support and 9. Overall quality of life. All these dimensions were referred to the last two weeks and answered based on a Likert scale from 1 to 5, where higher scores reflect poorer perceived health. An overall score was obtained from the sum of all the dimensions excepting item 5 that, due to its bipolar structure, requires a different reading from the rest of the dimensions [13]. The HRQoL instrument showed a suitable Cronbach's Alpha (0.77).

Acceptance and Action Questionnaire II for HD patients (AAQHD-II). This questionnaire was adapted from the original AAQ-II [14] to the context of HD treatment. It assessed the level of PI in the presence of certain thoughts (items 2 and 3), fears (item 6), treatment guidelines (items 4 and 5), situations related to the treatment of HD (item 1) and the effect of treatment guidelines on the patient's life (item 7). Scores were obtained by a 5-point Likert type scale $(1=$ Never true, $2=$ Rarely true, $3=$ Sometimes true, $4=$ Often true, $5=$ Always true). Cronbach's Alpha (0.72) was calculated grouping items into a single factor as in the original questionnaire.

Hospital Anxiety and Depression Scale (HADS), in the Spanish version of Terol et al. [15]. This scale has previously shown adequate psychometric properties in several groups of patients, including those in HD treatment in both international and Spanish studies [16,17]. Therefore, we used this instrument to assess emotional responses to anxiety and depression with or without medical and psychiatric conditions but excluding patients' somatic-type symptoms $[17,18]$. Patients' scores were calculated after the completion of fourteen items classified into two subscales, one for anxiety and one for depression, following a 4-point Likert response format, where the higher the score, the greater the presence of anxiety or depression. The Cronbach's Alpha (0.83) resulted suitable for both subscales.

\subsection{Statistical Analysis}

The sample was divided after the selection of a cut-off point from the total score of each HADS subscale. This cut-off was set at 8 points for both scales, where scores $\geq 8$ determined patients with presence or a likely presence of depressive or anxious condition.

Results were expressed as mean \pm standard deviation (SD) for continuous variables with normal distribution, median [25th percentile-75th percentile] for those with non-normal distribution and \% for categorical variables. Sociodemographic, clinical, psychological and quality of life-related variables were compared between groups for both depression and anxiety, using Student's $t$, Mann-Whitney's $U$ and Chi-square tests according to the nature of the variables. For the identification of predictive factors for anxiety and depression development, variables presenting statistical differences between groups or clinically relevant were included in univariate and multivariate logistic analyses. Linearity of the logit was tested for each variable included [19].

All statistical analyses were performed using the SPSS statistical package version 19.0 (IBM, Armonk, NY, USA). The level of statistical significance was set at $p<0.05$.

\section{Results}

\subsection{Baseline Characteristics of Study Participants}

Almost $40 \%$ of the 186 patients included in the study were women while the mean age was $70 \pm 13.8$. Regarding sociodemographic factors, $64.5 \%$ of the population was 
married or sharing their lives with a partner and had a low level of education (51.1\% with no studies and $31.2 \%$ with primary education). Most of the patients (97.8\%) were retired.

According to the groups determined by the HADS subscales scores, 52 patients $(27.9 \%)$ had or probably had a depressive or an anxiety disorder (the proportions found for both conditions were identical). We also observed that $34 \%$ of the patients were taking medication for affective disorders, mainly anxiolytics and/or antidepressants.

\subsection{Baseline Characteristics of Study Participants by the Presence of Depression}

Those cases with identified or probable depression were represented by a higher percentage of women, less proportion of married patients and more comorbid conditions compared to the non-depression group. Regarding the results from the psychological assessments in these depressive patients, higher scores for all HRQoL dimensions, PI and greater anxiety and intake of psychotropic drugs were noticed. Additionally, significant changes were detected in some clinical parameters as decreased values for albumin, sodium and calcium serum levels but also in body composition indexes (FTI increased, LTI decreased) (Table 1).

Table 1. Baseline characteristics of study population according to the depressive state.

\begin{tabular}{|c|c|c|c|c|}
\hline & & Non-Depressive Group & Depressive Group & \multirow{2}{*}{$p$-Value } \\
\hline & & $N=134$ & $N=52$ & \\
\hline \multicolumn{5}{|l|}{ Sociodemographic } \\
\hline \multirow{4}{*}{ Hemodialysis clinic } & FMC-San Rafael & $47.0 \%$ & $36.5 \%$ & \multirow{4}{*}{0.506} \\
\hline & FMC-Pintor Ga Güijo & $19.4 \%$ & $26.9 \%$ & \\
\hline & FMC-Cabra & $26.9 \%$ & $26.9 \%$ & \\
\hline & FMC-Palma del Río & $6.7 \%$ & $9.6 \%$ & \\
\hline Sex, women & & $29.9 \%$ & $63.5 \%$ & $<0.001$ \\
\hline Age (years) & & $69.0 \pm 14.6$ & $73.1 \pm 11.1$ & 0.070 \\
\hline Marital status & Married/with domestic partner & $70.1 \%$ & $50.1 \%$ & 0.010 \\
\hline \multirow{4}{*}{ Educational level } & No schooling & $49.3 \%$ & $55.8 \%$ & \multirow{4}{*}{0.398} \\
\hline & Primary school & $34.3 \%$ & $23.1 \%$ & \\
\hline & High school & $9.7 \%$ & $15.4 \%$ & \\
\hline & University & $6.7 \%$ & $5.8 \%$ & \\
\hline \multirow{3}{*}{ Employment status } & Unknown & $0.7 \%$ & $0.0 \%$ & \multirow{3}{*}{0.452} \\
\hline & Unemployed & $2.2 \%$ & $0.0 \%$ & \\
\hline & Retired & $97.0 \%$ & $100.0 \%$ & \\
\hline \multicolumn{5}{|l|}{ Quality of life } \\
\hline \multirow{10}{*}{$\begin{array}{l}\text { Health-related Quality of } \\
\text { Life (HRQoL) }\end{array}$} & Physical Fitness & $3(3-4)$ & $4(4-5)$ & $<0.001$ \\
\hline & Feelings & $2(1-3)$ & $3(2-4)$ & $<0.001$ \\
\hline & Daily Life Activities & $2(1-3)$ & $3(3-4)$ & $<0.001$ \\
\hline & Social Activities & $1(1-2)$ & $3(1,2-4)$ & $<0.001$ \\
\hline & Changes in Health Status & $3(2-3)$ & $3(3-4)$ & 0.002 \\
\hline & Health Status & $3(3-4)$ & $4(3-4)$ & $<0.001$ \\
\hline & Pain & $2(1-4)$ & $4(2.2-4)$ & $<0.001$ \\
\hline & Social Support & $2(2-3)$ & $3(2-3.7)$ & 0.001 \\
\hline & Quality of Life & $2(2-3)$ & $3(3-4)$ & $<0.001$ \\
\hline & Total score & $19(16-22)$ & $25.5(23-30)$ & $<0.001$ \\
\hline
\end{tabular}


Table 1. Cont.

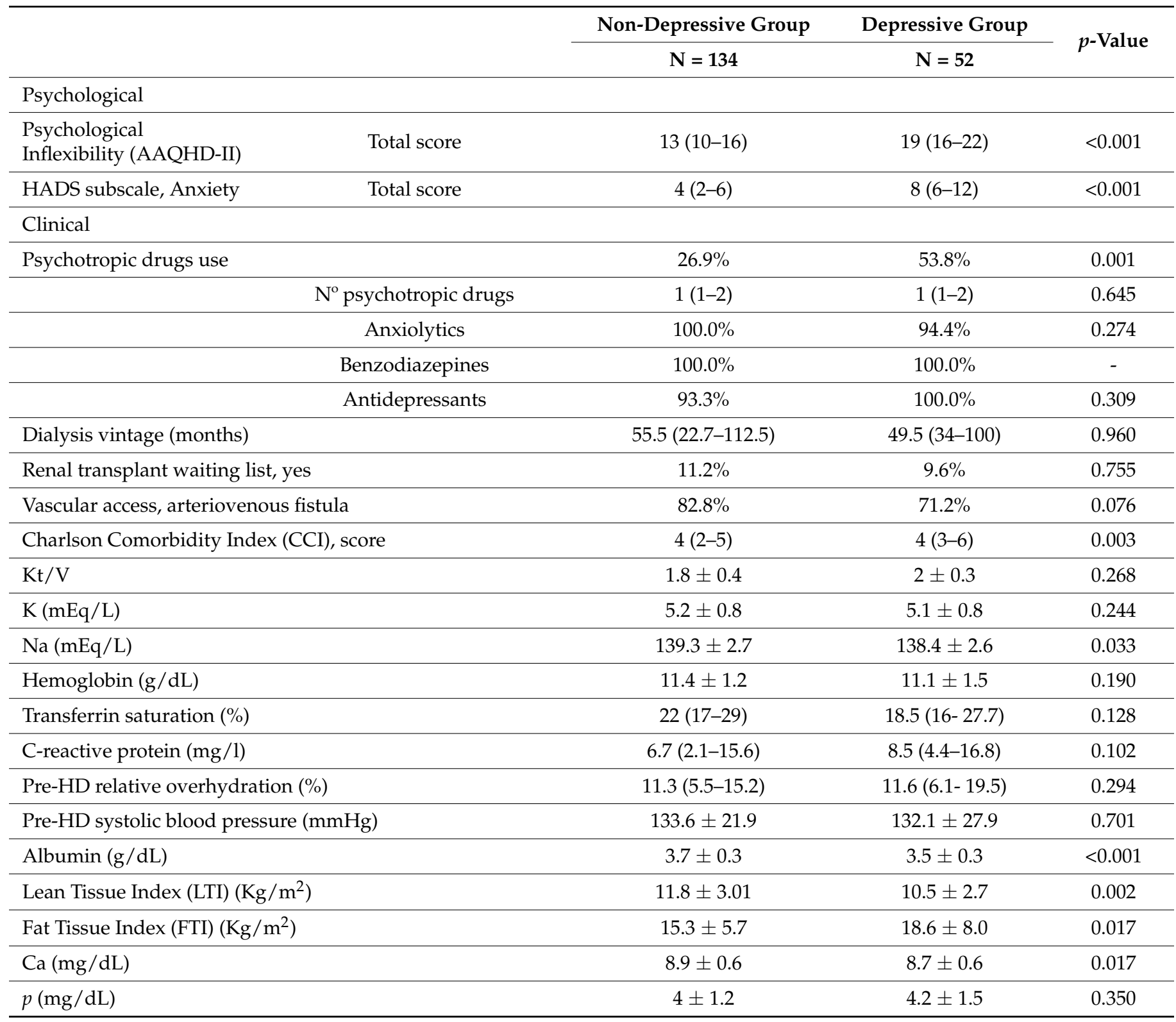

Note: Values expressed as mean $\pm \mathrm{SD}$, median (P25-P75) or frequency (\%). Depressive group was defined by patients presenting scores $\geq 8$ points in HADS depression subscale. Similarly, non-depressive group corresponds to those patients who scored $<8$ points in HADS.

\subsection{Baseline Characteristics of Study Participants by the Presence of Anxiety}

Within the group of patients with identified or probable anxiety, almost $60 \%$ were women, obtained worse HRQoL scores (emphasizing the items Feelings, Activities of daily living, Social activities, Changes in health status and Health status areas) and registered higher PI and presence of depression. This group of patients showed less frequency of arteriovenous fistula as vascular access and slight decreases in hemoglobin, albumin and calcium serum levels compared to those patients without anxiety (Table 2). 
Table 2. Baseline characteristics of study population according to the anxious state.

\begin{tabular}{|c|c|c|c|c|}
\hline & & Non-Anxious Group & Anxious Group & \multirow{2}{*}{$p$} \\
\hline & & $N=134$ & $\mathrm{~N}=52$ & \\
\hline \multicolumn{5}{|l|}{ Sociodemographics } \\
\hline \multirow{4}{*}{ Hemodialysis clinic } & FMC-San Rafael & $45.5 \%$ & $40.4 \%$ & \multirow{4}{*}{0.563} \\
\hline & FMC-Pintor Ga Güijo & $22.4 \%$ & $19.2 \%$ & \\
\hline & FMC-Cabra & $26.1 \%$ & $28.8 \%$ & \\
\hline & FMC-Palma del Río & $6 \%$ & $11.5 \%$ & \\
\hline Sex, women & & $31.3 \%$ & $59.6 \%$ & $<0.001$ \\
\hline Age (years) & & $70.4 \pm 13.2$ & $69.6 \pm 15.5$ & 0.754 \\
\hline Marital status & Married/with domestic partner & $66.4 \%$ & $59.6 \%$ & 0.384 \\
\hline \multirow{4}{*}{ Educational level } & No schooling & $48.5 \%$ & $57.7 \%$ & \multirow{4}{*}{0.477} \\
\hline & Primary school & $34.3 \%$ & $23.1 \%$ & \\
\hline & High school & $10.4 \%$ & $13.5 \%$ & \\
\hline & University & $6.7 \%$ & $5.8 \%$ & \\
\hline \multirow{3}{*}{ Employment status } & Unknown & $0.7 \%$ & $0 \%$ & \multirow{3}{*}{0.806} \\
\hline & Unemployed & $1.5 \%$ & $1.9 \%$ & \\
\hline & Retired & $97.8 \%$ & $98.1 \%$ & \\
\hline \multicolumn{5}{|l|}{ Quality of life } \\
\hline \multirow{10}{*}{$\begin{array}{l}\text { Health-related Quality of } \\
\text { Life (HRQoL) }\end{array}$} & Physical Fitness & $4(3-4)$ & $4(3-4)$ & 0.072 \\
\hline & Feelings & $1(1-2)$ & $3,5(3-4)$ & $<0.001$ \\
\hline & Daily Life Activities & $2(1-3)$ & $3(2.25-4)$ & $<0.001$ \\
\hline & Social Activities & $1(1-2)$ & $2(1-4)$ & $<0.001$ \\
\hline & Changes in Health Status & $3(2.7-3)$ & $3(3-4)$ & 0.011 \\
\hline & Health Status & $3(3-4)$ & $4(3-4)$ & 0.051 \\
\hline & Pain & $3(1-4)$ & $3(1-4)$ & 0.162 \\
\hline & Social Support & $2(2-3)$ & $2.5(2-3,7)$ & 0.237 \\
\hline & Quality of life & $2(2-3)$ & $3(2-4)$ & $<0.001$ \\
\hline & Total score & $20(16.7-23)$ & $24.5(21.2-28.7)$ & $<0.001$ \\
\hline \multicolumn{5}{|l|}{ Psychological } \\
\hline $\begin{array}{l}\text { Psychological Inflexibility } \\
\text { (AAQHD-II) }\end{array}$ & Total score & $13(10-17)$ & $18(15-22)$ & $<0.001$ \\
\hline HADS subscale, Depression & Total score & $4(2-6)$ & $8(5.2-10)$ & $<0.001$ \\
\hline \multicolumn{5}{|l|}{ Clinical } \\
\hline \multirow[t]{5}{*}{ Psychotropic drugs use } & & $30.6 \%$ & $44.2 \%$ & 0.079 \\
\hline & $\mathrm{N}^{\mathrm{o}}$ psychotropic drugs & $1(1-2)$ & $1(1-2)$ & 0.972 \\
\hline & Anxiolytics & $96.2 \%$ & $100 \%$ & 0.474 \\
\hline & Benzodiazepines & $100 \%$ & $100 \%$ & - \\
\hline & Antidepressants & $100 \%$ & $90.9 \%$ & 0.181 \\
\hline \multicolumn{2}{|l|}{ Dialysis vintage (months) } & $56.5(26-104)$ & $45(28.25-104.5)$ & 0.467 \\
\hline \multicolumn{2}{|c|}{ Renal transplant waiting list, yes } & $10.4 \%$ & $11.5 \%$ & 0.829 \\
\hline \multicolumn{2}{|c|}{ Vascular Access, arteriovenous fistula } & $85.1 \%$ & $65.4 \%$ & 0.003 \\
\hline \multicolumn{2}{|c|}{ Charlson Comorbility Index (CCI) score } & $4(2-5)$ & $4(3-5)$ & 0.387 \\
\hline
\end{tabular}


Table 2. Cont.

\begin{tabular}{|c|c|c|c|}
\hline & Non-Anxious Group & Anxious Group & \multirow{2}{*}{$p$} \\
\hline & $\mathrm{N}=134$ & $\mathrm{~N}=52$ & \\
\hline $\mathrm{Kt} / \mathrm{V}$ & $1.9 \pm 0.4$ & $1.9 \pm 0.4$ & 0.571 \\
\hline $\mathrm{K}(\mathrm{mEq} / \mathrm{L})$ & $5.2 \pm 0.8$ & $5.2 \pm 0.8$ & 0.626 \\
\hline $\mathrm{Na}(\mathrm{mEq} / \mathrm{L})$ & $139.2 \pm 2.9$ & $138.8 \pm 2.3$ & 0.387 \\
\hline Hemoglobin $(\mathrm{g} / \mathrm{dL})$ & $11.5 \pm 1.4$ & $11.0 \pm 1.2$ & 0.024 \\
\hline Transferrin saturation (\%) & $22(16-29.2)$ & $21(16.2-28)$ & 0.758 \\
\hline C-reactive protein $(\mathrm{mg} / \mathrm{L})$ & $6.8(2.2-15.1)$ & $9.3(3.7-19.8)$ & 0.073 \\
\hline Pre-HD relative overhydration (\%) & $11.5(5.3-15.3)$ & $11.1(6.3-18.9)$ & 0.458 \\
\hline Pre-HD systolic blood pressure (mmHg) & $134.5 \pm 21.2$ & $129.9 \pm 29.0$ & 0.242 \\
\hline Albumin $(\mathrm{g} / \mathrm{dL})$ & $3.7 \pm 0.3$ & $3.6 \pm 0.3$ & 0.003 \\
\hline Lean tissue index $(\mathrm{LTI})\left(\mathrm{Kg} / \mathrm{m}^{2}\right)$ & $11.5 \pm 3.0$ & $11.2 \pm 2.9$ & 0.472 \\
\hline Fat tissue index $(\mathrm{FTI})\left(\mathrm{Kg} / \mathrm{m}^{2}\right)$ & $15.6 \pm 5.9$ & $17.8 \pm 7.9$ & 0.129 \\
\hline $\mathrm{Ca}(\mathrm{mg} / \mathrm{dL})$ & $8.9 \pm 0.6$ & $8.6 \pm 0.7$ & 0.003 \\
\hline$p(\mathrm{mg} / \mathrm{dL})$ & $4 \pm 1.2$ & $4.2 \pm 1.4$ & 0.262 \\
\hline
\end{tabular}

Note: Values expressed as mean $\pm \mathrm{SD}$, median (P25-P75) or frequency (\%). Anxious group was defined by patients who obtained scores $\geq 8$ points in HADS anxiety subscale. Similarly, non-anxious group is represented by patients whose scores were $<8$ points in the scale.

\subsection{Predictors of Depression and Anxiety in HD Patients}

Univariate logistic analyses showed the influence of different variables on the depressive (Dep) and anxious states (Anx) in our population. Male sex (Dep: OR 0.2; Anx: OR 0.3), albumin (Dep: OR 0.1; Anx: OR 0.2) and calcium serum levels (Dep: OR 0.5; Anx: OR 0.4 ) were significantly associated to the presence of these mental disorders (all variables described presented $p$-values < 0.01). Moreover, higher HRQoL scores (Dep: OR 1.4; Anx: OR 1.2) and/or PI (Dep: OR 1.3; Anx: OR 1.2) seemed to prompt both conditions (Tables 3 and 4 ).

Table 3. Univariate and multivariate logistic analyses. Regression models performed to identify predictive factors for depressive state in patients on HD treatment.

\begin{tabular}{|c|c|c|c|c|}
\hline & \multicolumn{2}{|c|}{ Univariate Logistic Regression } & \multicolumn{2}{|c|}{ Multivariate Logistic Regression } \\
\hline & OR (CI, 95\%) & $p$-Value & OR (CI, 95\%) & $p$-Value \\
\hline Sex, men & $0.2(0.1-0.5)$ & $<0.001$ & $1.1(0.3-3.7)$ & 0.869 \\
\hline Marital status, married/with domestic partner & $0.4(0.2-0.8)$ & 0.011 & $0.3(0.1-0.9)$ & 0.025 \\
\hline Health-related Quality of Life (HRQoL score) & $1.4(1.3-1.6)$ & $<0.001$ & $1.3(1.2-1.5)$ & $<0.001$ \\
\hline Psychological inflexibility (AAQHD-II score) & $1.3(1.2-1.4)$ & $<0.001$ & $1.2(1.1-1.4)$ & $<0.001$ \\
\hline HADS subscale score, anxiety & $1.4(1.2-1.5)$ & $<0.001$ & $1.1(0.9-1.3)$ & 0.167 \\
\hline Charlson Comorbility Index (CCI) score & $1.3(1.1-1.6)$ & 0.004 & $1.4(1-1.9)$ & 0.051 \\
\hline Psychotropic drugs users & $3.2(1.6-6.2)$ & 0.001 & $0.5(0.2-1.8)$ & 0.318 \\
\hline Albumin (g/dL) & $0.1(0-0.4)$ & $<0.001$ & $0.1(0.2-0.8)$ & 0.027 \\
\hline $\mathrm{Na}(\mathrm{mEq} / \mathrm{L})$ & $0.9(0.8-1)$ & 0.035 & $1.0(0.8-1.2)$ & 0.681 \\
\hline $\mathrm{Ca}(\mathrm{mg} / \mathrm{dL})$ & $0.5(0.3-0.9)$ & 0.020 & $0.7(0.3-2.3)$ & 0.721 \\
\hline Lean tissue index $(\mathrm{LTI})\left(\mathrm{Kg} / \mathrm{m}^{2}\right)$ & $0.8(0.7-1)$ & 0.009 & $0.9(0.7-1)$ & 0.097 \\
\hline Fat tissue index (FTI) $\left(\mathrm{Kg} / \mathrm{m}^{2}\right)$ & $1.1(1-1.1)$ & 0.004 & $1(0.9-1)$ & 0.659 \\
\hline
\end{tabular}


After the inclusion of all significant variables from the aforementioned analyses and those clinically relevant into multivariate analyses, we confirmed that higher HRQoL scores $(\mathrm{OR} 1.3 ; p<0.001)$ predicted the development of depression in HD patients while having a partner (OR $0.3 ; p=0.025)$ and serum albumin levels (OR $0.1 ; p=0.027)$ were associated with a lower presence of this condition (Table 3 ). Depression as comorbidity represented a risk factor for anxiety state (OR 1.2; $p=0.001$ ) while calcium serum levels (OR $0.5 ; p=0.039$ ) seemed to protect this mental condition. Interestingly, we found that the PI was associated to an increased risk of suffering both, depression or anxiety (Dep: OR 1.2, $p<0.001$ and Anx: OR 1.1; $p=0.002$ ) (Table 4).

Table 4. Univariate and multivariate logistic analyses. Regression models performed to identify predictive factors for anxiety state in patients on HD treatment.

\begin{tabular}{|c|c|c|c|c|}
\hline & \multicolumn{2}{|c|}{ Univariate Logistic Regression } & \multicolumn{2}{|c|}{ Multivariate Logistic Regression } \\
\hline & OR (CI, 95\%) & $p$-Value & OR (CI, 95\%) & $p$-Value \\
\hline Sex, men & $0.3(0.2-0.6)$ & 0.001 & $0.6(0.3-1.41)$ & 0.267 \\
\hline Age (years) & $1(0.9-1)$ & 0.752 & $1(0.9-1)$ & 0.259 \\
\hline Health-related Quality of Life (HRQoL) & $1.2(1.1-1.3)$ & $<0.001$ & $1.1(0.9-1.2)$ & 0.286 \\
\hline Psychological Inflexibility (CAAH-II) & $1.2(1.1-1.3)$ & $<0.001$ & $1.1(1-1.2)$ & 0.002 \\
\hline HADS subscale, depression & $1.3(1.2-1.5)$ & $<0.001$ & $1.2(1.1-1.4)$ & 0.001 \\
\hline Psychotropic drugs users & $1.8(0.9-3.5)$ & 0.081 & $1(0.4-2.5)$ & 0.989 \\
\hline HD vintage (months) & $1(0.9-1)$ & 0.584 & $1(0.9-1)$ & 0.778 \\
\hline Waiting list for kidney transplant, included & $0.9(0.3-2.5)$ & 0.829 & $1.1(0.2-4.9)$ & 0.895 \\
\hline Vascular Access, catheter & $3(1.4-6.3)$ & 0.004 & $1.6(0.5-5.2)$ & 0.406 \\
\hline $\mathrm{Kt} / \mathrm{V}$ & $1.3(0.6-2.7)$ & 0.569 & $1(0.9-1)$ & 0.747 \\
\hline Hemoglobin (g/dL) & $0.8(0.6-1)$ & 0.026 & $0.7(0.5-1)$ & 0.053 \\
\hline C-reactive protein (mg/l) & $1(0.9-1)$ & 0.094 & $1(0.9-1)$ & 0.275 \\
\hline Albumin (g/dL) & $0.2(0.1-0.6)$ & 0.005 & $0.7(0.1-3)$ & 0.626 \\
\hline $\mathrm{Ca}(\mathrm{mg} / \mathrm{dL})$ & $0.4(0.3-0.8)$ & 0.004 & $0.5(0.3-1)$ & 0.039 \\
\hline Pre-HD systolic blood pressure (mmHg) & $1(0.9-1)$ & 0.418 & $1(0.9-1)$ & 0.403 \\
\hline
\end{tabular}

Note: OR, Odds ratio; CI, Confidence interval.

\section{Discussion}

The present study collected important data regarding prevalence of depression and anxiety in patients with CKD on HD treatment. The results obtained from our study population showed that more than a quarter of the patients evaluated presented with depression and to the same extent anxiety. These rates were similar to those found in other previous studies [2,20-23] and confirmed the actual need to take an in-depth look into the psycho-affective aspects of HD patients [24]. In our analysis, women showed a higher rate of depression than men, a common finding as women are more likely to suffer from affective disorders [25]. However, these gender differences disappeared when we included in the multiple regression analyses greater determinants as marital state, quality of life and PI.

Serum albumin levels were determined as a risk factor of depression in our multiple regression analysis, a finding which could support two previous studies from Taiwan [26] and Brazil that confirmed the clinical relevance of [27] the influence of depression on appetite as a rational for a significantly worse nutritional status in HD patients. In this sense, our results would also reinforce the suggestion of Friend et al. to take seriously the association between depression and nutritional status in HD units due to its additive effect on patients' mortality [28]. Furthermore, as proposed by other authors like Abdulan 
et al., depression would be a consequence of malnutrition especially in elderly patients undergoing HD [29].

Among the clinical parameters associated to altered mental status, we observed decreased serum calcium and sodium levels. It seems that decreased sodium levels could elicit depressive symptoms in animal models [30]. In addition, some evidences described depression and stress as possible modulators acting on sodium levels through different metabolic pathways [31]. As for calcium, previous research on patients with psychiatric disorders did not find solid relations between serum calcium levels and the presence of depression [32,33]. However, a recent study has pointed to a possible association of low-calcium dietary intake and the presence of both depression and anxiety in young adults [34]. In our study, biochemical changes related to these electrolytes were showed as a risk factor in the univariate analyses but not in the multivariate models when they were adjusted by other variables. We suggest that fluctuations in sodium and calcium levels are common and were more likely related to the patients' nutritional status. Even so, it is clear that further studies are needed to elucidate the influence of balanced/unbalanced electrolytes serum levels on the mental health in patients with CKD.

Detection of a depressive disorder in patients with CKD can be challenging since symptoms may be mistaken or a consequence from uremia [21]. Thus, an effective and early approach to these conditions' results are essential as untreated depression: (1) lead to poorer outcomes for these patients and (2) could also affect both, the adherence to the different treatments for CKD and their commitment to implement and maintain the recommendations for healthy living habits [35,36]. It would be of interest for future studies to quantify how much lifestyle factors (physical activity, different nutritional habits ... etc.) and the quality of dialysis could influence changes in body mass composition in HD patients with or without altered mental status [37].

Unlike depression, the incidence and role of anxiety in CKD has been less studied [7]. However, in our study, this condition was associated with a decline in quality of life standards. Previous studies already highlighted this concern in patients with CKD [1,7], finding that anxiety affected quality of life negatively and directly, and not only as a byproduct of a depressive picture. However, the multivariate regression of the present study shows how quality of life loses its predictive power when analyzed including other factors, such as PI.

Regarding the use of medication for affective disorders, there were no differences between groups which could be interpreted as these drugs did not affected the patients' emotional state. However, it should be noteworthy that patients can show high scores on anxiety and depression scales even when they are following a concomitant treatment with anxiolytics and/or antidepressants. Pharmacological treatments may be effective for the management of the most physiological symptoms derived from affective disorders, but cannot result enough to tackle their cognitive and emotional components [38]. This condition could be much more aggravated in HD patients who feel already anxious by their own HD treatment and other factors like transportation needs, or experience adverse intra- or post-dialysis events.

Different techniques (cognitive-behavioral interventions, mindfulness-based therapies or psychosocial interventions) have shown their effectiveness in improving the psychoaffective state of patients with CKD, the adherence to their medical prescriptions and the HD clinical outcomes [39-43]. In this line, our results reveal the considerable number of variables (clinical, psychological, social, emotional) that surround the patient on HD treatment. The accumulated evidence until now on the relevance and value of psychological care in patients with CKD is driving, although more slowly than desired, the implementation of Psychonephrology as a bridging discipline. The influence of mediators such as the quality of life, the PI or other biochemical parameters in two common affective disorders like depression or anxiety force to the development of new therapeutic approaches on this field. Based on our results, we truly believe that the integration of psychotherapies as part 
of the current HD treatment programs would benefit patients' clinical and psychological parameters, and thus, their clinical outcomes.

This is the largest Spanish study on the subject so far and analyzes 186 HD patients in four clinics. Multidisciplinary care in clinical practice has allowed a systematic collection of clinical, nutritional and psychological parameters with a high degree of standardization and good data quality. In addition, it has focused on transdiagnostic aspects of clinical psychology, such as PI. Although PI has not received attention in this type of population, it is especially relevant due to its idiosyncratic problems such as lack of adherence to treatment. However, the study also has some limitations. Firstly, due to its cross-sectional design, we could analyze associations between variables but could not set a causal link. Secondly, a higher sample size and the inclusion of patients from other regions of Spain would confirm and provide more precise data. Lastly, this study was not designed to assess the influence of other possible confounding factors such as chronic pain, specific comorbidities not related to CKD, inflammation markers and/or other mental disorders. These factors should be included in future studies.

In conclusion, our results evidence the actual need of HD units formed by multidisciplinary teams trained not only in CKD management but also in the assessment of mental health status as part of an integrated HD treatment. Moreover, this is the first time that the PI is associated directly with the risk of development of both mental disorders, depression or anxiety, in HD patients.

Author Contributions: Conceptualization, C.J.D.-D., A.R.B. and R.R.S.; data curation, A.L.-H., B.D.E., O.L.G. and A.R.B.; formal analyses, S.S.-G., A.L.-H., O.L.G., M.d.1.S.R. and A.R.B.; investigation, C.J.D.-D., S.S.-G., B.D.E., M.d.1.S.R., I.B.G. and R.R.S.; methodology, C.J.D.-D., S.S.-G., A.L.-H., O.L.G., M.d.I.S.R., I.B.G., A.R.B. and R.R.S.; project administration, C.J.D.-D., B.D.E., I.B.G. and R.R.S.; writing—original draft, C.J.D.-D. and B.D.E.; writing—review and editing, S.S.-G., A.L.-H., M.d.l.S.R., I.B.G., A.R.B. and R.R.S. All authors made significant contributions to drafting and revising the article, provided intellectual content of critical importance to the work and approved the final version to be published. All authors have read and agreed to the published version of the manuscript.

Funding: This research received no external funding.

Institutional Review Board Statement: The study was conducted according to the guidelines of the Declaration of Helsinki and approved by the Institutional Review Board (or Ethics Committee) of Hospital Universitario Reina Sofía (protocol code 0710-N-17) June 2017.

Informed Consent Statement: Informed consent was obtained from all subjects involved in the study.

Data Availability Statement: Data are available upon reasonable request to the corresponding author.

Acknowledgments: The researchers would like to thank Fresenius Medical Care patients from the Córdoba clinics for their participation in the study.

Conflicts of Interest: The authors declare no conflict of interest.

\section{References}

1. Cukor, D.; Cohen, S.D.; Peterson, R.A.; Kimmel, P.L. Psychosocial aspects of chronic disease: ESRD as a paradigmatic illness. J. Am. Soc. Nephrol. 2007, 18, 3042-3055. [CrossRef]

2. Cukor, D.; Coplan, J.; Brown, C.; Peterson, R.A.; Kimmel, P.L. Course of depression and anxiety diagnosis in patients treated with hemodialysis: A 16-month follow-up. Clin. J. Am. Soc. Nephrol. 2008, 3, 1752-1758. [CrossRef] [PubMed]

3. Drayer, R.A.; Piraino, B.; Reynolds, C.F.; Houck, P.R.; Mazumdar, S.; Bernardini, J.; Shear, M.K.; Rollman, B.L. Characteristics of depression in hemodialysis patients: Symptoms, quality of life and mortality risk. Gen. Hosp. Psychiatry 2006, $28,306-312$. [CrossRef]

4. Kimmel, P.L.; Cukor, D. Anxiety Symptoms in Patients Treated with Hemodialysis: Measurement and Meaning. Am. J. Kidney Dis. 2019, 74, 145-147. [CrossRef] [PubMed]

5. Schouten, R.W.; Haverkamp, G.L.; Loosman, W.L.; Chandie Shaw, P.K.; van Ittersum, F.J.; Smets, Y.F.C.; Vleming, L.J.; Dekker, F.W.; Honig, A.; Siegert, C.E.H. Anxiety symptoms, mortality and hospitalization in patients receiving maintenance dialysis: A cohort study. Am. J. Kidney Dis. 2019, 74, 158-166. [CrossRef] [PubMed] 
6. Kurella, M.; Kimmel, P.L.; Young, B.S.; Chertow, G.M. Suicide in the United States end-stage renal disease program. J. Am. Soc. Nephrol. 2005, 16, 774-781. [CrossRef] [PubMed]

7. Cohen, S.D.; Cukor, D.; Kimmel, P.L. Anxiety in Patients Treated with Hemodialysis. Clin. J. Am. Soc. Nephrol. 2016, 11, 2250-2255. [CrossRef]

8. Gilbert, K.E.; Tonge, N.A.; Thompson, R.J. Associations between depression, anxious arousal and manifestations of psychological inflexibility. J. Behav. Ther. Exp. Psychiatry 2019, 62, 88-96. [CrossRef] [PubMed]

9. Bond, F.W.; Hayes, S.C.; Baer, R.A.; Carpenter, K.M.; Guenole, N.; Orcutt, H.K.; Waltz, T.; Zettle, R.D. Preliminary psychometric properties of the Acceptance and Action Questionnaire-II: A revised measure of psychological inflexibility and experiential avoidance. Behav. Ther. 2011, 42, 676-688. [CrossRef]

10. Levin, M.E.; MacLane, C.; Daflos, S.; Seeley, J.; Hayes, S.C.; Biglan, A.; Pistorello, J. Examining psychological inflexibility as a transdiagnostic process across psychological disorders. J. Contextual Behav. Sci. 2014, 3, 155-163. [CrossRef] [PubMed]

11. Pérez-García, R.; Palomares-Sancho, I.; Merello-Godino, J.I.; Aljama-García, P.; Bustamante-Bustamante, J.; Luño, J.; MaduellCanals, F.; Martín-de Francisco, A.L.; Martín-Malo, A.; Mirapeix-i-Vicens, E.; et al. Epidemiological study of 7316 patients on haemodialysis treated in FME clinics in Spain, using data from the EuCliD ${ }^{\circledR}$ database: Results from years 2009-2010. Nefrologia 2012, 32, 743-753.

12. Arenas, M.D.; Moreno, E.; Reig, A.; Millán, I.; Egea, J.J.; Amoedo, M.L.; Gil, M.T.; Sirvent, A.E. Evaluation of health-related quality of life (HRQL) based on information from Coop/Wonca sheets in hemodialysis patients. Nefrologia 2004, 24, 470-479. [PubMed]

13. Van Weel, C. Functional status in primary care: COOP/WONCA charts. Disabil. Rehabil. 1993, 15, 96-101. [CrossRef] [PubMed]

14. Delgado-Domínguez, C.J.; García, J.V.; Ruiz, F.J.; Espejo, B.D.; Guerrero, P.C.; Sánchez, E.R.; Jurado, N.G.; Bello, A.R.; Sánchez, R.R. Psychological inflexibility and clinical impact: Adaptation of the acceptance and action questionnaire-II in a sample of patients on haemodialysis treatment. Nefrología 2020, 40, 160-170. [CrossRef]

15. Terol, M.C.; López-Roig, S.; Rodríguez-Marín, J.; Martín-Aragón, M.; Pastor, M.A.; Reig, M.T. Propiedades psicométricas de la Escala Hospitalaria de Ansiedad y Depresión (HAD) en población Española/Hospital Anxiety and Depression Scale (HAD): Psychometric properties in Spanish population. Ansiedad y Estrés 2007, 13, 163-176.

16. Perales-Montilla, C.M.; Duschek, S.; Reyes-del Paso, G.A. Influencia de los factores emocionales sobre el informe de síntomas somáticos en pacientes en hemodiálisis crónica: Relevancia de la ansiedad. Nefrologia 2013, 33, 816-825.

17. Untas, A.; Aguirrezabal, M.; Chauveau, P.; Leguen, E.; Combe, C.; Rascle, N. Anxiety and depression in hemodialysis: Validation of the Hospital Anxiety and Depression Scale (HADS). Nephrol. Ther. 2009, 5, 193-200. [CrossRef] [PubMed]

18. Pérez Domínguez, T.S.; Rodríguez Pérez, A.; Buset Ríos, N.; Rodríguez Esparragón, F.; García Bello, M.A.; Pérez Borges, P.; Parodis López, Y.; Rodríguez Pérez, J.C. Psiconefrología: Aspectos psicológicos en la poliquistosis renal autosómica dominante. Nefrologia 2011, 31, 716-722.

19. Hosmer, D.W.; Lemeshow, S. Applied Logistic Regression, 3th ed.; John Wiley \& Sons: Hoboken, NJ, USA, 2013; ISBN 978-0-47058247-3.

20. Chen, C.K.; Tsai, Y.C.; Hsu, H.J.; Wu, I.W.; Sun, C.Y.; Chou, C.C.; Lee, C.C.; Tsai, C.R.; Wu, M.S.; Wang, L.J. Depression and suicide risk in hemodialysis patients with chronic renal failure. Psychosomatics 2020, 51, 528. [CrossRef]

21. Feroze, U.; Martin, D.; Reina-Patton, A.; Kalantar-Zadeh, K.; Kopple, J.D. Mental health, Depression, and Anxiety in Patients on Maintenance Dialysis. Iran. J. Kidney Dis. 2010, 4, 173-180. [PubMed]

22. Rodríguez-Rey, R.; García-Llana, H.; Ruiz-Álvarez, M.P.; Gómez-Gómez, A.; Del Peso, G.; Selgas, R. Multicenter Validation of the Emotional State Instrument for Dialysis Patients. Nur. Res. 2019, 68, 39-47. [CrossRef]

23. Watnick, S.; Kirwin, P.; Mahnensmith, R.; Concato, J. The prevalence and treatment of depression among patients starting dialysis. Am. J. Kidney Dis. 2003, 41, 105-110. [CrossRef] [PubMed]

24. García-Llana, H.; Bajo, M.A.; Barbero, J.; Selgas, R.; Del Peso, G. The Communication and Bioethical Training (CoBiT) Program for assisting dialysis decision-making in Spanish ACKD units. Psychol. Health Med. 2017, 22, 474-482. [CrossRef] [PubMed]

25. Altemus, M.; Sarvaiya, N.; Neill Epperson, C. Sex differences in anxiety and depression clinical perspectives. Front. Neuroendocrinol. 2014, 35, 320-330. [CrossRef]

26. Jong, I.C.; Tsai, H.B.; Lin, C.H.; Ma, T.L.; Guo, H.R.; Hung, P.H.; Hung, K.Y. Close correlation between the ankle-brachial index and symptoms of depression in hemodialysis patients. Int. Urol. Nephrol. 2017, 49, 1463-1470. [CrossRef]

27. Alencar, S.B.V.; de Lima, F.M.; Dias, L.D.A.; Dias, V.D.A.; Lessa, A.C.; Bezerra, J.M.; Apolinário, J.F.; de Petribu, K.C. Depression and quality of life in older adults on hemodialysis. Braz. J. Psychiatry 2020, 42, 195-200.

28. Friend, R.; Hatchett, L.; Wadhwa, N.K.; Suh, H. Serum albumin and depression in end-stage renal disease. Adv. Perit Dial. 1997, 13, 155-157.

29. Abdulan, I.M.; Onofriescu, M.; Stefaniu, R.; Mastaleru, A.; Mocanu, V.; Alexa, I.D.; Covic, A. The predictive value of malnutrition for functional and cognitive status in elderly hemodialysis patients. Int. Urol. Nephrol. 2019, 51, 155-162. [CrossRef]

30. Morris, M.J.; Na, E.S.; Johnson, A.K. Mineralocorticoid receptor antagonism prevents hedonic deficits induced by a chronic sodium appetite. Behav. Neurosci. 2010, 124, 211-224. [CrossRef]

31. Goldstein, P.; Leshem, M. Dietary sodium, added salt, and serum sodium associations with growth and depression in the U.S. general population. Appetite 2014, 79, 83-90. [CrossRef] 
32. Sharma, A.; Schray, A.; Bartolovic, M.; Roesch-Ely, D.; Aschenbrenner, S.; Weisbrod, M. Relationship between serum calcium and neuropsychological performance might indicate etiological heterogeneity underlying cognitive deficits in schizophrenia and depression. Psychiatry Res. 2017, 252, 80-86. [CrossRef]

33. Grützner, T.M.; Listunova, L.; Fabian, G.A.; Kramer, B.A.; Flach, D.; Weisbrod, M.; Roesch-Ely, D.; Sharma, A. Serum calcium levels and neuropsychological performance in depression and matched healthy controls: Reversal of correlation a marker of the aging cognitive clock? Psychoneuroendocrinology 2018, 91, 198-205. [CrossRef] [PubMed]

34. Alkhatatbeh, M.J.; Abdul-Razzak, K.K.; Khwaileh, H.N. Poor sleep quality among young adults: The role of anxiety, depression, musculoskeletal pain, and low dietary calcium intake. Perspect. Psychiatr. Care 2021, 57, 117-128.

35. Aghakhani, N.; Fattahi, Y. Depression in Hemodialysis Patients. Saudi J. Kidney Dis. Transpl. 2019, 30, 261-262. [CrossRef] [PubMed]

36. Rojas-Villegas, Y.; Ruíz-Martínez, A.O.; González-Sotomayor, R.; Rojas-Villegas, Y.; Ruíz-Martínez, A.O.; González-Sotomayor, R. Anxiety and depression on therapeutic adherence in patients with kidney disease. Rev. Psicol. 2017, 26, 65-77.

37. Zhang, M.; Kim, J.C.; Li, Y.; Shapiro, B.B.; Porszasz, J.; Bross, R.; Feroze, U.; Upreti, R.; Martin, D.; Kalantar-Zadeh, K.; et al. Relation between anxiety, depression, and physical activity and performance in maintenance hemodialysis patients. J. Ren. Nutr. 2014, 24, 252-260. [CrossRef]

38. Cuijpers, P.; van Straten, A.; van Oppen, P.; Andersson, G. Are psychological and pharmacologic interventions equally effective in the treatment of adult depressive disorders? A meta-analysis of comparative studies. J. Clin. Psychiatry 2008, 69, 1675-1685. [CrossRef]

39. Grigoriou, S.S.; Karatzaferi, C.; Sakkas, G.K. Pharmacological and Non-pharmacological Treatment Options for Depression and Depressive Symptoms in Hemodialysis Patients. Health Psychol. Res. 2015, 3, 1811. [CrossRef] [PubMed]

40. Thomas, Z.; Novak, M.; Platas, S.G.T.; Gautier, M.; Holgin, A.P.; Fox, R.; Segal, M.; Looper, K.J.; Lipman, M.; Selchen, S.; et al. Brief Mindfulness Meditation for Depression and Anxiety Symptoms in Patients Undergoing Hemodialysis: A Pilot Feasibility Study. Clin. J. Am. Soc. Nephrol. 2017, 12, 2008-2015. [CrossRef]

41. Cukor, D. Use of CBT to treat depression among patients on hemodialysis. Psychiatr. Serv. 2007, 58, 711-712. [CrossRef]

42. Duarte, P.S.; Miyazaki, M.C.; Blay, S.L.; Sesso, R. Cognitive-behavioral group therapy is an effective treatment for major depression in hemodialysis patients. Kidney Int. 2009, 76, 414-421. [CrossRef]

43. Cukor, D.; Ver Halen, N.; Asher, D.R.; Coplan, J.D.; Weedon, J.; Wyka, K.E.; Saggi, S.J.; Kimmel, P.L. Psychosocial intervention improves depression, quality of life, and fluid adherence in hemodialysis. J. Am. Soc. Nephrol. 2014, 25, 196-206. [CrossRef] [PubMed] 